\title{
OS AVANÇOS TECNOLÓGICOS E A PRECARIZAÇÃO DAS RELAÇÕES DE TRABALHO: A NECESSIDADE DE ESPAÇOS TRANSNACIONAIS PROTETIVOS
}

\author{
TECHNOLOGICAL ADVANCEMENTS AND THE PRECARIOUSNESS OF LABOR \\ RELATIONS: THE NEED FOR PROTECTIVE TRANSNATIONAL SPACES
}

\section{LOS AVANCES TECNOLÓGICOS Y LA PRECARIZACIÓN DE LAS RELACIONES DE TRABAJO: LA NECESIDAD DE ESPACIOS TRANSNACIONALES PROTECTORES}

\author{
Maira Angélica Tonial ${ }^{1}$
}

\section{Marcos Leite Garcia²}

Licença CC BY:

Artigo distribuído sob os termos Creative Commons, permite uso e distribuição irrestrita em qualquer meio desde que $o$ autor credite a fonte original.

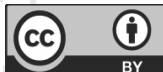

\begin{abstract}
Resumo: Tecendo considerações preliminares sobre o fenômeno da quarta revolução industrial e seus impactos nas relações laborais, o presente artigo traz o registro de uma abordagem sobre os direitos fundamentais, em especial os sociais. Aborda-se, mais especificamente, desde a origem até a mitigação dos direitos fundamentais sociais trabalhistas. Sustenta-se, a partir da constatação da recente e cada vez mais crescente precarização, a necessidade de Estados fortes, que possam barrar os impactos negativos dos fenômenos de globalização da economia, bem como se argumenta pela necessidade de criação de espaços transnacionais aparelhados de modo a servir a defesa dos direitos fundamentais, além de sua constante concretização.
\end{abstract}

Palavras-chave: Direitos Sociais Fundamentais. Plataformas de Capitalismo. Precarização. Transnacionalismo.

Abstract: Making preliminary considerations about the phenomenon of the fourth industrial revolution and its impacts on labor relations, this paper presents the record of an approach to fundamental rights, especially social rights. More specifically, it addresses fundamental social rights at work from their origin through to their mitigation. Based on the observation of their recent and increasing precariousness, it supports the need for strong states that can block the negative impacts of the phenomenon of globalization of the economy, as well as the need to create transnational spaces equipped to defend fundamental rights, in addition to their constant concretization.

Keywords: Fundamental Social Rights. Platforms of capitalism. Precariousness. Transnationalism.

Resumen: Hacer consideraciones preliminares sobre el fenómeno de la cuarta revolución industrial y sus impactos en las relaciones laborales, el presente artículo tras el registro de un abordaje sobre los derechos

\footnotetext{
1 Doutoranda em Ciências Jurídicas e Sociais pela Univali, mestre em Direito pela Unissinos, graduada pela UPF. Professora de Direito do Trabalho na UPF. E-mail: mairatonial@upf.br.

2 Pós-Doutor pela Universidade Federal de Santa Catarina, Doutor em Direito pela Universidade Complutense de Madrid-Espanha, graduado em Direito pela Universidade Federal de Santa Catarina. Professor do PPG da Univali e UPF. E-mail: mleitegarcia@terra.com.br.
} 


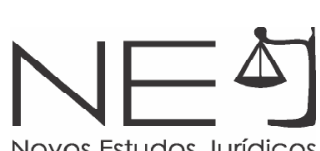

fundamentales, especialmente los sociales. Aborda, más específicamente, desde el origen hasta la mitigación de los derechos laborables fundamentales sociales. Basado, a partir de la constatación reciente y cada vez más creciente precarización, la necesidad de Estados fuertes, que puedan impedir los impactos negativos de los fenómenos de la globalización económica como la necesidad de creación de espacios transnacionales aparejados para servir a la defensa de los derechos fundamentales, además de su constante realización.

Palabras clave: Derechos Sociales Fundamentales. Plataformas de Capitalismo. Precarización. Transnacionalismo.

\section{INTRODUÇÃO}

O presente artigo objetiva a análise dos avanços tecnológicos contemporâneos e seus impactos no mundo do trabalho, em especial na precarização das relações laborais. Para tanto, inicia-se a abordagem realizando uma breve contextualização dos impactos dos mecanismos tecnológicos no âmbito laboral, com ênfase no fenômeno da plataformização das relações laborais.

Na sequência, registra-se a noção de direitos fundamentais, em especial os sociais trabalhistas, seu surgimento e desenvolvimento no passar dos anos, para, ao final, tergiversar sobre a questão da precarização das relações laborais e o retrocesso social. Adiante, finaliza-se o presente artigo com uma abordagem do fenômeno global e a necessidade de abertura de espaços que sejam transnacionais, a fim de que se assegure a resistência a direitos fundamentais.

Utiliza-se do método de abordagem bibliográfico e do método de pesquisa da sociologia compreensiva.

\section{DIREITO DO TRABALHO E SUA CONSTRUÇÃO HISTÓRICA}

Inicialmente, para que seja possível discorrer sobre o objeto da presente pesquisa, necessário se faz que se proceda a um recorte histórico de contextualização do surgimento dos direitos sociais, em especial o Direito do Trabalho, seja na esfera internacional, seja na esfera nacional.

Essa contextualização revela-se importante, pois, sem entender os fundamentos sobre os quais se assentou a necessidade da ingerência do Estado na esfera privada dos seus cidadãos, não se pode aquilatar o fenômeno atual de precarização de direitos sociais.

Assim, se, num primeiro momento, o homem produtivo valia-se apenas de sua força de produção para sua própria subsistência, com o passar do tempo, os propósitos e as necessidades alteraram-se. 
Basicamente pode-se, de forma bastante sintética, afirmar que a primeira forma de trabalho subordinado foi a escravocrata. Interessante que, em sua essência, esse processo tinha cunho político, pois eram escravizados aqueles que perdiam as batalhas nas disputas por territórios e por mantimentos.

Mais adiante na história, com transformações ocorridas, de índole econômico/social, a comunidade passou a se organizar na forma de feudos, nos quais o meio de subsistência - a terra - era de propriedade de poucos. A maioria dos homens e das mulheres trabalhadores dos feudos laborava no cultivo da terra, porém na condição de "servos", ainda de maneira subordinada à prestação de serviços, sem interferência do Estado e sem qualquer direito trabalhista assegurado. Como explica Rifkin, "Las condiciones de arrendamiento establecían que los campesinos entregaran al señor un porcentaje de su cosecha o que trabajaran las tierras del señor - además de las suyas - durante todo el año". ${ }^{3}$

No entanto, as precárias condições a que foram submetidos os trabalhadores da época obrigaram a que alguns deles abandonassem os feudos em que laboravam e onde prestavam servilismo a seus senhores feudais e migrassem para polos de vida comum, processo que deu início à formação das cidades e do sistema estatal de então.

Nesses centros comuns, a atividade laborativa desenvolvia-se em pequenas oficinas, germens das fábricas contemporâneas. No entanto, a situação pouco se alterou se comparada na vida aos feudos e do ponto de vista da relação e do ambiente de trabalho, pois os trabalhadores apenas mudaram sua referência espacial, uma vez que ainda permaneciam sob ordens do "mestre" e sem quaisquer condições dignas que comportassem sua circunstância de trabalhador.

Essas oficinas, denominadas corporações de ofício, possuíam em seu quadro aprendizes, companheiros e mestres (proprietários), que dividiam as atividades na confecção de produtos. Segundo Nascimento, "As corporações mantinham com os trabalhadores uma relação de tipo bastante autoritário e que se destinava mais à realização de seus interesses do que à proteção dos trabalhadores". ${ }^{4}$ Sem condições adequadas, o clima de instabilidade agravou-se, clamando por uma intervenção do Estado. Paralelamente a isso, inicia-se um processo transformativo de produção, conforme refere Nascimento:

3 RIFKIN, Jeremy. La sociedad de coste marginal cero: El internet de las cosas, el procomún colaborativo y el eclipse del capitalismo. Barcelona: Paidós, 2014. p. 34.

4 NASCIMENTO, Amauri Mascaro. Iniciação ao Direito do Trabalho. 31. ed. São Paulo: LTR, 2005. p. 48. 
A transformação das manufaturas em indústrias e a Revolução Industrial do século XVIII expandiu o drama do trabalho do operário, labor esse prestado sem a proteção de um sistema de leis que o regulamentassem, intensificou-se a questão social [...]. ${ }^{5}$

A interferência do Estado tornou-se necessária, pois adventos de novas tecnologias também influíram neste processo de crise social. Rifkin explica que a tecnologia do vapor gerado marcou o início de uma nova matriz energética "la imprenta a vapor y la locomotora a vapor - que proporcionó una megaplataforma tecnológica de uso general para la Primera Revolución Industrial". ${ }^{6}$

Com o cenário nada agradável e sujeito a condições indignas, o sentimento de revolta foi crescendo dia após dia entre os trabalhadores. A união de esforços começou a tomar corpo, surgindo as primeiras manifestações coletivas reivindicativas de melhores condições de trabalho, obrigando o Estado a acionar mecanismos legislativos protetivos, tendo por fundamento "a ideia de justiça social, cada vez mais difundida como reação contra a questão social". ${ }^{7}$

Pode-se, assim, aduzir que o Direito do Trabalho começa seu caminho nesse momento histórico, no início de século XIX, e que "o Direito do Trabalho é, pois, produto cultural do século XIX e das transformações econômico-sociais e políticas ali vivenciadas" ${ }^{8}$. Interessante também destacar a criação da Organização Internacional do Trabalho (OIT), importante passo na internacionalização do Direito do Trabalho.

Neste sentido, Bertaso reforça "Qual seja, em todos os momentos direitos humanos e cidadania potencializaram as lutas daqueles que demandam por justiça e que vivem em situações extremas de indignidade coletiva". ${ }^{9}$

Ocorre, porém, que a intervenção estatal se mostrou tímida e não suficiente para abarcar as necessidades apresentadas pela comunidade, num contexto pós-guerra e de desenvolvimento de novas tecnologias, com a premência de se assegurar a proteção de direitos fundamentais.

Mais recentemente na história, com a evolução tecnológica, o mundo do trabalho ganha novos vernizes. A metalurgia, a siderurgia e a química surgem como novas formas de enfrentar o processo produtivo, e um novo desafio inicia-se para os trabalhadores e para o Estado: o advento de uma segunda Revolução Industrial. Desse modo, 
En los últimos dos decenios del siglo XIX, cuando la Primera Revolución Industrial llegaba a su apogeo, empezó a nacer una Segunda Revolución Industrial en Norteamérica y en Europa. El descubrimiento del petróleo, la invención del motor de combustión interna y la introducción del teléfono dieron lugar a un nuevo complejo de energía/comunicaciones que dominaría el siglo XX.10

Os direitos fundamentais, embora tutelados de forma precária, continuam sendo cobrados do Estado como políticas afirmativas, a fim de proteger direitos laborais. Porém um novo evento marca a história no início da década de 1970: a computadorização, que inaugura uma nova fase nas relações trabalhistas. A produção passa por um novo processo transformativo - denominado Terceira Revolução Industrial - e, com ela, o desemprego estrutural assola novamente a sociedade, retirando do homem seus postos de trabalho, horizontalizando a produção e revelando a robotização como uma realidade a ser experimentada.

Agora, vive-se sob as angústias de uma quarta Revolução Industrial. A engenharia genética e a neurotecnologia alçam destaque neste novo cenário e, novamente, surge a necessidade de se ter um estado interventor, que tutele direitos sociais, visto que a exclusão alçará a marca de cinco milhões de vagas nos países mais industrializados do mundo, como anunciado no Fórum Mundial de Davos, em 2016. ${ }^{11}$

Se, no âmbito internacional, a evolução do mundo do trabalho deu-se dessa forma, no Brasil, o desenrolar da história foi um pouco diferente e em ritmos desconexos ao relatado. Pois, de um "descobrimento", em que a população local ficou subordinada à prestação de serviços e à exploração dos então "conquistadores", passou-se a um sistema de trabalho subordinado escravocrata, que deixa resquícios até hoje, como exposto por Souza. ${ }^{12}$ Somente em 1888, com a Lei Áurea, o Brasil pôde respirar a liberdade subordinativa. Esse fato foi um marco na história brasileira, encerrando um ciclo de muita dor e violência aos direitos humanos. Em passos lentos, a legislação trabalhista foi se formando e teve importante destaque na década de 1930, quando, sob o comando de Getúlio Vargas, houve impulsos significativos em termos de consolidação de direitos sociais, vindo culminar, em 1943, com a edição da Consolidação das Leis do Trabalho (CLT).

Com o transcorrer da história, e aos poucos mais direitos sociais, foram se avolumando e sendo acrescidos ao rol protetivo das relações de trabalho, reafirmando sua condição de direito social. Segundo Rimolo, "Trabalho enquanto direito social - La empleabilidad se convierte, en consecuencia, en un elemento de inclusión del individuo a la sociedad o, si se prefiere, en un factor de ciudadanía

11 O QUE É A 4 a revolução industrial e como ela deve afetar nossas vidas. BBC News, 22 out. 2016. Disponível em: <https://www.bbc.com/ portuguese/geral-37658309>. Acesso em: 2018.

12 SOUZA, Jessé. A elite do atraso. Da escravidão à Lava Jato. Rio de Janeiro: Leya, 2017. 


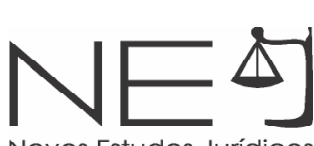

Novos Estudos Jurídicos

laboral y social". ${ }^{13}$ Grande impulso ocorreu com a proclamação da Constituição Federal de 1988, que alçou papel fundamental ao Direito do Trabalho, pois o elevou à condição de direito fundamental e, para tanto, travestido com regras e com garantias especiais, juntamente com educação, saúde, trabalho, moradia, lazer, segurança, previdência social, proteção à maternidade e à infância e a assistência aos desamparados ${ }^{14}$. A dignidade do homem pelo trabalho passa a atingir novo status: "Dignificar a dignidade passa antes por não dar-lhe uso ornamental." 15

Embora se tenha conhecimento de que entre o texto da lei e a realidade exista uma distância significativa ${ }^{16}$, a todos foi imposta a constante busca por melhores condições de trabalho, como determina o artigo $7^{\circ}$ da Constituição Federal, a fim de atingir princípios básicos como a erradicação da pobreza, visando a atingir o fundamento insculpido no seu artigo $1^{\circ}$, qual seja: dignidade a todo cidadão. ${ }^{17}$ Nesse sentido, Streck "Deixar vir o novo à presença: esse é o desafio"18.

Nesse contexto, os direitos fundamentais merecem especial proteção do Estado, a fim de que sejam tutelados e protegidos em face de interferências externas e também internas, visto que a atual Constituição, dita "cidadã", possui esse caráter compromissário com a sociedade brasileira, coibindo, assim, eventual retrocesso social.

Assim, foram erigidos à condição de cláusulas pétreas (artigo 60, parágrafo $4^{\circ}$, inciso IV da Constituição Federal ${ }^{19}$ ) e possuem especial proteção, como adverte Sarlet, sob "pena de restar esvaziada a sua particular dignidade no âmbito da teoria constitucional contemporânea". ${ }^{20}$

Assim, vale-se das palavras de Rubio, para quem, "Em que pese existir um reconhecimento da importância dos direitos fundamentais ou dos direitos humanos constitucionalizados, os mecanismos de não aplicabilidade, e a ausência de garantias conviventes estão sempre na ordem do dia."21

13 RIMOLO, Jorge Rosenbaum. Los Derechos Fundamentales del Trabajo en el Marco de las Reformas del Nuevo Orden Económico. Cadernos PROLAM/USP, São Paulo, ano 2, vol. 2, n. 3, p. 25-43, 2003. p. 28.

14 Constituição da República Federativa do Brasil de 1988: "Art. $6^{\circ}$. São direitos sociais a educação, a saúde, a alimentação, o trabalho, a moradia, o transporte, o lazer, a segurança, a previdência social, a proteção à maternidade e à infância, a assistência aos desamparados, na forma desta Constituição."

15 GIACOMUZZI, José Guilherme. Dignidade Humana e Direito Administrativo no STF: uma breve análise crítica. Revista Novos Estudos Jurídicos, v.20, n.02. maio - agosto 2015, Disponível em: www.univali.br/periodicos, p. 470. Acesso em: 2019

16 Constituição da República Federativa do Brasil de 1988: "Art. $7^{\circ}$. São direitos dos trabalhadores urbanos e rurais, além de outros que visem à melhoria de sua condição social: [...]IV - salário mínimo, fixado em lei, nacionalmente unificado, capaz de atender a suas necessidades vitais básicas e às de sua família com moradia, alimentação, educação, saúde, lazer, vestuário, higiene, transporte e previdência social, com reajustes periódicos que the preservem o poder aquisitivo, sendo vedada sua vinculação para qualquer fim; [...]".

17 Constituição da República Federativa do Brasil de 1988: "Art. $1^{\circ} \mathrm{A}$ República Federativa do Brasil, formada pela união indissolúvel dos Estados e Municípios e do Distrito Federal, constitui-se em Estado Democrático de Direito e tem como fundamentos: [...] III - a dignidade da pessoa humana; IV - os valores sociais do trabalho e da livre iniciativa".

18 STRECK, Lenio Luiz. Jurisdição Constitucional e Hermenêutica: Perspectivas e Possibilidades de Concretização dos Direitos Fundamentais Sociais no Brasil. Revista Novos Estudos Jurídicos. V. 8 - № 2, p. 259, maio/agosto, 2003. Disponível em: www.univali.br/periodicos, p. 908. Acesso em: 2019.

19 Constituição da República Federativa do Brasil de 1988: "Art. 60. A Constituição poderá ser emendada mediante proposta: [...] § $4^{\circ}$ Não será objeto de deliberação a proposta de emenda tendente a abolir: [...] IV - os direitos e garantias individuais."

20 SARLET, Ingo Wolofgang. Os Direitos Fundamentais Sociais como "Cláusulas Pétreas". Cadernos de Direito Piracicaba, v. 3, n. 5, p. 78-97, jul./dez. 2003. p. 80.

21 RUBIO, David Sánchez. Fazendo e desfazendo os direitos humanos. Tradutor: Clóviz Gorczevski. Santa Cruz: Edunisc, 2010. p. 29. 
Dessa forma, deverão as constituições salvaguardar os direitos trabalhistas diante das ameaças externas. Logo, no âmbito internacional, seria de bom alvedrio que as bases de trabalho digno fossem preservadas pelo fortalecimento de relações trabalhistas globais.

No entanto, em especial no ponto que interessa à presente pesquisa, deve-se focar no fenômeno da precarização das relações laborais e a proteção social, em razão da ausência de regulação e de políticas públicas, em especial de âmbito transnacional. Para tanto, tratar-se-á dos direitos fundamentais (em especial daqueles que protegem as relações laborais) que impactam diretamente no mundo do trabalho globalizado e, na sequência, traça-se uma abordagem de como se deve agir a fim de concretizar essa proteção em âmbito transnacional.

\section{A CONSOLIDAÇÃO DOS DIREITOS SOCAIS E A PRECARIZAÇÃO EM ÂMBITO GLOBAL}

Se a todos é dado o direito de conhecer sua história, ao Direito do Trabalho aplica-se a mesma regra. Embora a Constituição Federal de 1988 tenha alçado ao trabalhador rol extenso de direitos socais, insculpidos no artigo $7^{\circ}$, eles se encontram, atualmente, em processo de flexibilização e desconstrução, como consequência do movimento liberal que se implantou no mundo de maneira global. Assim, propõe-se, neste momento, abordar o processo de formação dos direitos fundamentais, para, posteriormente, fazer-se menção ao movimento de precarização e quais as possíveis alternativas de resistência.

Garcia menciona que a origem e a fundamentação dos direitos humanos se confundem e, analisando a questão semântica e técnica das expressões, assim se manifesta:

Na nossa opinião, três são expressões as corretas para serem usadas atualmente: direitos humanos, direitos fundamentais e direitos do homem. Respaldamos nossa opinião no consenso geral existente na doutrina especializada no sentido de que os termos direitos humanos e direitos do homem se utilizam quando fazemos referência àqueles direitos positivados nas declarações e convenções internacionais, e o termo direitos fundamentais para aqueles direitos que aparecem positivados ou garantidos no ordenamento jurídico de um Estado. ${ }^{22}$

Assim, definidos os termos em que ocorrerá a presente abordagem, necessária se faz uma breve análise da evolução dos direitos fundamentais.

22 GARCIA, Marcos Leite. O processo de formação do ideal dos Direitos Fundamentais: alguns aspectos destacados da gênese do conceito. In: CONGRESSO NACIONAL CONPEDI, XIV, 2006, Manaus. Anais. Disponível em: http://www.publicadireito.com.br/conpedi/manaus/arquivos/ anais/XIVCongresso/052.pdf>. Acesso em: 2018. p. 04. 
Para tanto, inicialmente, vale-se de Peces-Barba, que refere, em suas lições, às linhas de evolução. Segundo sua concepção, os direitos fundamentais passam por processos: positivação, generalização, internacionalização e especificação. Interessante em sua abordagem é o fato de que frisa com detalhes o processo de positivação ${ }^{23}$, como se deu essa passagem, em especial no que tange aos direitos de primeira geração; logo em seguida, abrange a forma generalista ${ }^{24}$ como se estendem a todos os membros da comunidade a gama de direitos (dando início ao processo social - direitos de segunda geração); no terceiro momento, aborda questões relacionadas à esfera internacional, ${ }^{25}$ como forma de universalização, e, por último, a especificação, ${ }^{26}$ abarcando direitos difusos e de terceira geração, e a forma com que a pessoa é vista em sua individualidade.

Da mesma forma, interessante mencionar a Declaração de Direitos Humanos de Viena, de 1993, que, reiterando a Declaração de 1948, em seu parágrafo 50,27 afirma a qualidade que atribui aos direitos humanos sua condição de internacionalização e de universalização.

Nesse aspecto, interessante se torna para a presente pesquisa o fenômeno da precarização dos direitos fundamentais, em especial dos direitos sociais laborais, devido à precarização das relações de trabalho. Nessa nova ordem mundial, os espaços nacionais ficam dissolvidos na ordem global. ${ }^{28}$

Contemporaneamente, vive-se em um contexto globalizado, cujos reflexos de determinadas condutas já não se refletem apenas no âmbito local, mas principalmente em âmbito global. É o que aduz Florão:

O crescimento da interdependência entre os povos e países da superfície terrestre, que alguns preferem denominar de 'Aldeia Global', pois parece que o Planeta está ficando menor, e todos parecem se conhecer (assistem a programas de televisão, ou através da Internet, ficam sabendo o que ocorre no mundo todo, no mesmo dia e, muitas vezes, no ato do conhecimento), se deve ao enorme desenvolvimento nos meios de transporte, comunicação, nas viagens e no turismo internacional, nas trocas comerciais entre os países. ${ }^{29}$

PECES-BARBA, Gregorio. Curso de Derechos Fundamentales: teoría general. Madrid: Universidad Carlos III de Madrid, 1995. p. 156. PECES-BARBA, 1995. p. 160. PECES-BARBA, 1995. p. 173. PECES-BARBA, 1995. p. 180.

"5. Todos os direitos humanos são universais, interdependentes e inter-relacionados. A comunidade internacional deve tratar os direitos humanos globalmente de forma justa e equitativa, em pé de igualdade e com a mesma ênfase". DECLARAÇÃO E PROGRAMA DE AÇÃO DE VIENA, de 1993. DECLARAÇÃO E PROGRAMA DE AÇÃO DE VIENA. Conferência Mundial sobre Direitos Humanos Viena, 14-25 de Junho de 1993. Disponível em: <https://www.oas.org/dil/port/1993\%20Declara\%C3\%A7\%C3\%A30\%20e\% 20Programa\%20 de $\% 20$ Ac\%C3\%A7\%C3\%A30\%20adoptado\%20pela\%20Confer\%C3\%AAncia\%20Mundial\%20de\%20Viena\%20sobre\%20Direitos\%20 Humanos\%20em\%20junho\%20de\%201993.pdf>. Acesso em: 2019.

28 GORCZEVSKI, Clovis. A Iniludível necessidade de um estado interventivo para garantir, através da educação, a plena concretização dos direitos humanos no imprescindível Estado Liberal. Direitos Humanos e Participação Política, Porto Alegre, vol. III, p. 15-36, 2012. p.23. FLORÃO, Santo R. S. Introdução e Administração: Globalização e Empresa. 3. ed. Goiânia, Kelps, 2006. 
Como acirramento do comércio mundial, as grandes empresas buscam a competitividade em seus preços para que possam, com isso, ganhar mercado para a produção e para a distribuição de seus bens e serviços. Da mesma forma, assim agindo, podem introduzir novos processos produtivos que resultam em mais agilidade e baixo valor. Para Rifkin, "Esto les obliga a responder introduciendo sus propias innovaciones con el fin de aumentar su productividad y reducir sus precios en un ciclo que no tiene fin." ${ }^{30}$

Nesse contexto, para que se tenha efetividade na proteção dos direitos fundamentais e no estudo específico dos direitos sociais trabalhistas, deve-se, além de enfatizar o olhar universal dos direitos humanos, proceder a uma abordagem específica de setores da sociedade que se encontrem em situação de vulnerabilidade. Nesse sentido, países que se tornam meros servidores de mão de obra são potenciais vítimas da exclusão. Assim é que, para Bobbio, "O problema dos direitos fundamentais não é justificá-los, mas, sim, protegê-los." ${ }^{31}$

Nesse sentido de proteção dos direitos sociais, Stiglitz vai direto à ferida, quando aponta: "O número de pessoas vivendo na pobreza na verdade aumentou para quase 100 milhões. Isso aconteceu quase ao mesmo tempo em que a renda total do mundo cresceu a uma média anual de 2,5\%". 32

Esse dado demonstra que algo existe de equivocado na economia globalizada, ao mesmo tempo em que revela que direitos fundamentais estão à margem da proteção estatal e supraestatal. Assim, nas reflexões de Morin, a fragilidade torna-se latente: "De maneira geral, trata-se de reinserir a economia no social, no cultural, no humano, o que significa, fundamentalmente, colocar a economia em seu devido lugar como meio, e não como fim último da atividade humana." ${ }^{33}$

Em havendo a garantia a um trabalho digno, com boa remuneração e desenvolvido em condições salubres, permite-se que o desenvolvimento seja atingido de forma sustentável, como assegura Sen: "Com oportunidades sociais adequadas, os indivíduos podem efetivamente moldar seu próprio destino e ajudar uns aos outros". ${ }^{34}$

E, nesse sentido, importante trazer o pensamento de Dowbor, que, contrapondo os efeitos do processo de transnacionalização empresarial e econômica, sustenta estar a sociedade vivendo uma crise civilizatória, pois "Criou-se um hiato profundo entre os nossos avanços tecnológicos, que foram e continuam sendo espetaculares, e a nossa capacidade de convívio civilizado, que se estagna ou até regride". 35

$30 \quad$ RIFKIN, 2014. p. 12.

31 BOBBIO, Norberto. A era dos direitos. Tradutor: Carlos Nelson Coutinho. Rio de Janeiro: Campus, 2004. p.16.

32 STIGLITZ, Joseph E. Globalization and its Discontents. Nova York/Londres: WW Norton Company, 2003. p. 06

33 MORIN, Edgar. A via: para o futuro da humanidade. Tradutores: Edgard de Assis Carvalho; Mariza Perassi Bosco. Rio de Janeiro: Bertrand Brasil, 2013. p.155.

34 SEN, Amartya. Desenvolvimento como liberdade. 8. ed. São Paulo: Companhia das Letras, 2010. p. 26.

35 DOWBOR, Ladislau. A era do capital improdutivo: por que oito famílias têm mais riqueza do que a metade da população do mundo? São Paulo: Autonomia Literária, 2017. p. 09. 
As empresas que assumem um caráter transnacional preocupam-se em tornar seus produtos competitivos. Para tanto, em não sendo possível reduzir o valor da matéria-prima, atacam o que possuem de mais precioso, seus colaboradores, gerando uma massa de trabalhadores explorados e de poucos detentores dos meios de produção abonados. Nesse sentido, Scholz refere que "A espoliação da multidão é uma nova forma de exploração, executada por quatro ou cinco estrelas, que se apoia em uma massa global de milhões de trabalhadores em tempo real". ${ }^{36}$

Os direitos sociais somente poderão tornar-se efetivos se propiciarem condições materiais a todos. Conforme Martin,

El punto de partida de los derechos sociales debe ser la igualdad material. Este tipo deigualdad pretende crear los criterios materiales para llevar a cabo el valor solidariedad, crear las condiciones materiares para una liberdad posible para todos, y contribuir a la seguridad con la satisfacción de necesidades a quien no pueda hacerlo por su proprio esfuerzo. ${ }^{37}$

O terreno tornou-se fértil para a implantação de políticas flexibilizadoras, pois, como assevera Rubio, "É isso que vem ocorrendo com os processos de globalização neoliberal e de democratização restritiva: a lógica da acumulação do mercado anula o papel ativo das pessoas". ${ }^{38}$

E, na mesma toada, Stiglitz adverte que

O Estado-nação, que foi o centro do poder político e (em grande medida) econômico nos últimos 150 anos, está sendo espremido atualmente - de um lado, pelas forças da economia global e, de outro, pelas exigências políticas de devolução do poder. ${ }^{39}$

Seguindo os ditames preconizados pela OIT, de que sem justiça social não há paz, os rumos tomados pela atual política neoliberal deixam a desejar, pois ela fragiliza e desregulamenta direitos trabalhistas, ainda mais se levando em consideração que se está enfrentando uma revolução industrial que desalojará vários trabalhadores de seus postos de trabalho. Assim, como afirmam Souto Maior, Mendes e Severo, "Quebrar esse pacto significa, portanto, um erro histórico, uma traição com nossos antepassados e também assumir uma atitude de descompromisso com relação às gerações futuras". ${ }^{40}$

36 SCHOLZ, Trebor. Cooperativismo de plataforma: contestando a economia do compartilhamento corporativa. Tradutor: Rafael A. F. Zanatta. São Paulo: Elefante, 2016. p. 24.

37 MARTín, Nuria Belloso. Los derechos sociales en tiempos de crisis: un nuevo reto para el estado social. Direitos Humanos e Participação Política, Porto Alegre, vol. III, p. 37-74, 2012.p.49.

38 RUBIO, David Sánchez. Fazendo e desfazendo os direitos humanos. Tradutor: Clóviz Gorczevski. Santa Cruz: Edunisc, 2010. p. 43.

39 STIGLITZ, 2003. p. 85.

40 SOUTO MAIOR, Jorge Luiz; MOREIRA, Runílio M.; SEVERO, Valdete Souto. Dumping social nas relações de trabalho. São Paulo: LTr, 2012. p. 1. 
Na crítica de Raimar,

[...] o trabalhador é quem tem suportado, de modo visível, o custo deste enfrentamento entre diferentes centros de produção, o que pode ser demonstrado pela utilização cada vez mais frequente do chamado dumping social, prática condenável de desrespeito às garantias mínimas do trabalhador, como forma de reduzir custos de bens e serviços. ${ }^{41}$

Ao permitir que o mercado político/financeiro dite as regras do jogo, deixa-se de lado o aspecto social e, nesse sentido, pouca dúvida resta de quem efetivamente enfrenta o descaso.

\section{PROTEÇÃO TRANSNACIONAL}

Conforme se pode observar a partir dos apontamentos anteriores, as revoluções industriais ocorridas e em curso, baseadas em avanços tecnológicos, obrigam a sociedade a processar uma reestruturação em suas instituições.

Piovesan, realizando uma análise a respeito da proteção dos direitos humanos, manifesta que a proteção aos "[...] direitos humanos não deve se limitar ao domínio reservado do Estado, isto é, não deve se restringir à competência nacional exclusiva ou à jurisdição doméstica exclusiva, porque revela tema de legítimo interesse internacional." 42

Como aduz Pasold em suas reflexões,

A flexibilização dos direitos fundamentais corrobora a ação antiética promovida pelas empresas ou corporações transnacionais. O Estado transnacional deverá pautar sua formulação - política, econômica, social - pela proteção às pessoas pelos critérios adequados nos quais se percebem o significado das múltiplas inter-retroações entre as culturas do mundo. A partir dessa experiência do ser-com-outro participam interesses de cunho político preparados para elaborar esse novo espaço democrático. ${ }^{43}$ Segundo a autora, o tema de interesse então internacional possibilita que se relative a soberania estatal, à medida que intervenções nacionais são permitidas para assegurar a proteção dos direitos humanos em localidades cujo perigo de ameaça ou de ameaça concretizada se tornem prementes. Ainda, solidifica-se a concepção de que o homem, como sujeito de direitos, deve ser tutelado em esfera internacional. ${ }^{44}$

\footnotetext{
41 MACHADO, Raimar Rodrigues. Igualdade, liberdade contratual e exclusão, por motivo de idade, nas relações de emprego. Porto Alegre: Magister, 2011. p. 79.

42 PIOVESAN, Flavia. Direitos sociais, oportunidades e direitos civis e políticos. Sur, Rev. int. direitos humanos. São Paulo, v. 1, n. 1, p. 20-47, 2004. p. 23.

PASOLD, Cesar Luiz. (Coord.) Primeiros ensaios de Teoria do Estado e da Constituição. Curitiba: Juruá, 2010. p. 127.

PIOVESAN, 2004. p. 23.
} 


\section{Chacon explica:}

Na virada do século XX para o XXI, os Estados vão deixando de ser nacionais e plurinacionais e passam a ser - os que para isso dispõem de poder econômico e científico-tecnológico, portanto militar e político - Estados transnacionais: Seu poder econômico lhes é dado por suas empresas também transnacionais, no sentido, antes definido, de sediadas num Estado-nação e dele projetadas em outros. Empresa transnacional e Estado transnacional acompanham-se, braços da mesma culturacivilização que os gerou e mantém, cultura significando o que são os seus homens, e civilização, o que fazem, aquela seiva desta. ${ }^{45}$

Nesse sentido, Martin adverte que "La justicia transicional es una respuesta a las violaciones sistemáticas o generalizadas a los derechos humanos." ${ }^{46}$

Stelzer define a transnacionalização da seguinte maneira:

A Transnacionalização pode ser compreendida como um fenômeno reflexivo da globalização, que se evidencia pela desterritorialização dos relacionamentos político-sociais, fomentado por sistema econômico capitalista ultra valorizado, que articula ordenamento jurídico mundial à margem da soberania dos Estados. A transnacionalidade insere-se no contexto da globalização e liga-se fortemente com a concepção do transpasse estatal. Enquanto a globalização remete à idéia de conjunto, de globo, enfim, o mundo sintetizado como único; Transnacionalização está atada à referência de Estado permeável, mas tem na figura estatal a referência do ente em declínio. ${ }^{47}$

Atualmente, observa-se que os Estados não mais dispõem de força para combater os influxos de políticas econômicas em âmbito mundial. O resultado disso é a mitigação de direitos sociais. No caso específico do Direito do Trabalho, seguidas várias revoluções industriais e com uma em curso, políticas neoliberais associadas com o fenômeno da revolução tecnológica estão dizimando postos de trabalho.

E, ao que tudo indica, a revolução tecnológica é uma faceta irreversível desse processo, ao passo que é possível se adotarem políticas públicas mais humanas para o enfrentamento dessa realidade. Para Martin, "La problematica de las garantias de los derechos dociales se encuentra ineludiblemente unida al tema de las estrategias de Politicas publicas". ${ }^{48}$

CHACON, Vamireh. Globalização e Estados Transnacionais: relações internacionais no século XXI. São Paulo: SENAC, 2002. p. 19. MARTíN, Nuria Belloso. La justicia transicional: ¿La renuncia de lo irrenunciable? Quaestio luris, Rio de Janeiro, vol. 10, n. 01, 2017. p. 334. STELZER, Joana. O fenômeno da transnacionalização de dimensão Jurídica. In: CRUZ, Paulo Marcio; STELZER, Joana. (orgs.). Direito de transnacionalidade. Curitiba: Juruá, 2009. p. 21. 
A sociedade passou, passa e passará por profundas transformações. O mundo do trabalho sofreu, sofre e sofrerá os inflexos dessas mudanças culturais, sociais e econômicas. Em razão disso, os direitos sociais também sofrerão os impactos dessa nova era.

Nesse novo cenário, revela-se importante a utilização de mecanismos transnacionais para assegurar a proibição do retrocesso social, a mitigação de direitos, levando-se em conta, sobretudo, o que determina a OIT, por intermédio de Declaração Regulatória de Princípios e Direitos Fundamentais do Trabalho, celebrada em 19 de junho de 1998, que reconhece que a paz universal será possível com a existência de justiça social.

Tendo esta por objetivo de tutelar os direitos sociais naqueles países que ratifiquem suas convenções,

No âmbito da OIT, é interessante destacar a Declaração relativa aos princípios e direitos fundamentais do e no trabalho. Essa Declaração foi adotada em 1998 e por ela os Estados Membros, quer tenham ou não ratificados os convênios nela compreendidos, comprometem-se a respeitar e promover os direitos inseridos nas seguintes categorias: a liberdade de associação e a liberdade sindical e o efetivo reconhecimento do direito de negociação coletiva; a eliminação do trabalho forçado ou obrigatório; a abolição do trabalho infantil e, finalmente, a eliminação da discriminação no que diz respeito ao emprego e ocupação. ${ }^{49}$

Dessa forma, a busca de uma economia global que seja mais inclusiva é obrigação de todos, pois o crescimento econômico somente faz sentido se acompanhado do social. Conforme argumenta Sen, "Portanto, a contribuição do crescimento econômico tem de ser julgada não apenas pelo aumento de rendas privadas, mas também pela expansão de serviços sociais [...]". ${ }^{50}$

Tendo em vista a preocupação com o desenvolvimento sustentável e com a necessidade de espaços adequados de discussão, Garcia, com preocupação, destaca a necessidade de criação para espaços transnacionais que sejam eficientes para discussões de terceira geração:

O processo de internacionalização tradicional dos direitos humanos, a partir da criação dos sistemas internacionais de proteção dos direitos humanos - universal: ONU e regionais: OEA e Conselho de Europa - não têm se mostrado suficientes para a proteção dos direitos fundamentais de primeira e segunda geração e nem o serão para questões mais complexas como os de terceira geração. ${ }^{51}$

49 PAIXÃO, Cristiano; RODRIGUES, Douglas Alencar; CALDAS, Roberto Figueiredo (Coords.). Os novos horizontes do Direito. São Paulo: LTr, 2005. p. 354.

50 SEN, 2010. p.61.

51 GARCIA, Marcos Leite. Novos direitos fundamentais e demandas transnacionais. In: CONGRESSO NACIONAL CONPEDI, XIX, 2010, Fortaleza. p. 6735-6762. Anais. Disponível em: <http://www.publicadireito.com.br/conpedi/manaus/arquivos/anais/fortaleza/3681.pdf>. Acesso em: 2019. p. 6751. 
Dessa forma, a resistência torna-se necessária para controlar o impulso flexibilizador e, mais do que isso, a necessidade de espaços adequados de discussão se torna premente, visto que os fenômenos são transnacionais, sob pena de toda a legislação existente não ser suficiente para conter os influxos que estão em curso.

\section{CONSIDERAÇÕES FINAIS}

O presente estudo teve por intuito realizar, inicialmente, uma abordagem sobre o mundo do trabalho e suas transformações ao longo da história. O principal motivo de realizar tal digressão foi demonstrar a construção legal sobre a qual se assentaram a base social e os direitos laborais.

Seguiu-se a pesquisa, dando-se ênfase à necessidade da existência de diplomas legais fortes que amparem os direitos sociais de forma robusta, evitando assim a ingerência externa por empresas transnacionais. Em momento posterior à busca de esclarecimentos sobre o fenômeno globalizatório, cujas empresas transacionais têm puxado o processo econômico, denotando-se o gigantesco poderio econômico em determinadas situações, valem-se de seu poderio para forçar países, em situação de desenvolvimento, à realização de alterações em seus ordenamentos jurídicos.

Finaliza-se a abordagem com a explanação da necessidade de se criar espaços transnacionais capazes de conter os retrocessos sociais com a mitigação de normas trabalhistas, para que o desenvolvimento seja efetivamente sustentável e atenda aos anseios sociais.

\section{REFERÊNCIAS}

BERTASO, João Martins. CIDADANIA TRANSLOCAL: tecendo possibilidades. Revista Novos Estudos Jurídicos, v. 19, n.3, setembro - dezembro 2014, p. 904-925. Disponível em: www.univali.br/periodicos. Acesso em: 2019.

BOBBIO, Norberto. A era dos direitos. Tradutor: Carlos Nelson Coutinho. Rio de Janeiro: Campus, 2004.

CHACON, Vamireh. Globalização e Estados Transnacionais: relações internacionais no século XXI. São Paulo: SENAC, 2002.

DECLARAÇÃO E PROGRAMA DE AÇÃO DE VIENA. Conferência Mundial sobre Direitos Humanos Viena, 14-25 de Junho de 1993. Disponível em: < https://www.oas.org/dil/port/1993\%20Declara\%C3\%A7\%C3\%A30\%20e\%20Programa\%20 de\%20Ac\%C3\%A7\%C3\%A30\%20adoptado\%20pela\%20Confer\%C3\%AAncia\%20Mundial\%20de\%20Viena\%20sobre\%20 Direitos\%20Humanos\%20em\%20junho\%20de\%201993.pdf>. Acesso em: 2019.

DELGADO, Maurício Godinho. Curso de Direito do Trabalho. São Paulo: Ltr, 2006.

DOWBOR, Ladislau. A era do capital improdutivo: por que oito famílias têm mais riqueza do que a metade da população do mundo? São Paulo: Autonomia Literária, 2017.

FLORÃO, Santo R. S. Introdução e Administração: Globalização e Empresa. 3. ed. Goiânia: Kelps, 2006. 
GARCIA, Marcos Leite Garcia O processo de formação do ideal dos Direitos Fundamentais: alguns aspectos destacados da gênese do conceito. In: CONGRESSO NACIONAL CONPEDI, XIV, 2006, Manaus. Anais. Disponível em: http://www. publicadireito.com.br/conpedi/manaus/arquivos/anais/XIVCongresso/052.pdf>. Acesso em: 2018.

GARCIA, Marcos Leite. Novos direitos fundamentais e demandas transnacionais. In: CONGRESSO NACIONAL CONPEDI, XIX, 2010, Fortaleza. p. 6735-6762. Anais. Disponível em: <http://www.publicadireito.com.br/conpedi/manaus/arquivos/ anais/fortaleza /3681.pdf>. Acesso em: 2019.

GIACOMUZZI, José Guilherme. Dignidade Humana e Direito Administrativo no STF: uma breve análise crítica. Novos Estudos Jurídicos. v. 20, n.02, p. 430-473, maio - agosto 2015. Disponível em: www.univali.br/periodicos, p. 908 . Acesso em: 2019.

GORCZEVSKI, Clovis. A Iniludível necessidade de um estado interventivo para garantir, através da educação, a plena concretização dos direitos humanos no imprescindível Estado Liberal. Direitos Humanos e Participação Política, Porto Alegre, vol. III, p. 15-36, 2012.

MACHADO, Raimar Rodrigues. Igualdade, liberdade contratual e exclusão, por motivo de idade, nas relações de emprego. Porto Alegre: Magister, 2011.

MARTíN, Nuria Belloso. Los derechos sociales en tiempos de crisis: un nuevo reto para el estado social. Direitos Humanos e Participação Política, Porto Alegre, vol. III, p. 37-74, 2012.

MARTín, Nuria Belloso. La justicia transicional: ¿La renuncia de lo irrenunciable? Quaestio luris, Rio de Janeiro, vol. 10, n. $01,2017$.

MORIN, Edgar. A via: para o futuro da humanidade. Tradutores: Edgard de Assis Carvalho; Mariza Perassi Bosco. Rio de Janeiro: Bertrand Brasil, 2013.

NASCIMENTO, Amauri Mascaro. Iniciação ao Direito do Trabalho. 31. ed. São Paulo: LTR, 2005.

O QUE É A 4a revolução industrial e como ela deve afetar nossas vidas. BBC News, 22 out. 2016. Disponível em: <https:// www.bbc.com/portuguese/geral-37658309>. Acesso em: 2018.

PAIXÃO, Cristiano; RODRIGUES, Douglas Alencar; CALDAS, Roberto Figueiredo (Coords.). Os novos horizontes do Direito. São Paulo: LTr, 2005.

PASOLD, Cesar Luiz (Coord.) Primeiros ensaios de Teoria do Estado e da Constituição. Curitiba: Juruá, 2010.

PECES-BARBA, Gregorio. Curso de Derechos Fundamentales: teoría general. Madrid: Universidad Carlos III de Madrid, 1995.

PIOVESAN, Flavia. Direitos sociais, oportunidades e direitos civis e políticos. Sur, Rev. int. direitos humanos. São Paulo, v. 1, n. 1, p. 20-47, 2004

RIFKIN, Jeremy. La sociedad de coste marginal cero: El internet de las cosas, el procomún colaborativo y el eclipse del capitalismo. Barcelona: Paidós, 2014.

RIMOLO, Jorge Rosenbaum. Los Derechos Fundamentales del Trabajo en el Marco de las Reformas del Nuevo Orden Económico. Cadernos PROLAM/USP, São Paulo, ano 2, vol. 2, n. 3, p. 25-43, 2003.

RUBIO, David Sánchez. Fazendo e desfazendo os direitos humanos. Tradutor: Clóviz Gorczevski. Santa Cruz: Edunisc, 2010.

SARLET, Ingo Wolofgang. Os Direitos Fundamentais Sociais como "Clausulas Pétreas". Cadernos de Direito Piracicaba, v. 3, n. 5, p. 78-97, jul./dez. 2003.

SCHOLZ, Trebor. Cooperativismo de plataforma: contestando a economia do compartilhamento corporativa. Tradutor: Rafael A. F. Zanatta. São Paulo: Elefante, 2016.

SEN, Amartya. Desenvolvimento como liberdade. 8. ed. São Paulo: Companhia das Letras, 2010. 
SOUTOMAIOR, Jorge Luiz; MOREIRA, Runílio M.; SEVERO, Valdete Souto. Dumping social nas relações de trabalho. São Paulo: LTr, 2012.

SOUZA, Jessé. A elite do atraso. Da escravidão à Lava Jato. Rio de Janeiro: Leya, 2017.

STELZER, Joana. O fenômeno da transnacionalização de dimensão Jurídica. In: CRUZ, Paulo Marcio; STELZER, Joana. (orgs.). Direito de transnacionalidade. Curitiba: Juruá, 2009.

STIGLITZ, Joseph E. Globalization and its Discontents. Nova York/Londres: WW Norton Company, 2003.

STRECK, Lenio Luiz. Jurisdição Constitucional e Hermenêutica: Perspectivas e Possibilidades de Concretização dos Direitos Fundamentais Sociais no Brasil. Novos Estudos Jurídicos. v 8 - n² 2, página 257-301, maio/agosto 2003, Disponível em: www.univali.br/periodicos. Acesso em: 2019.

\section{$\Delta 1$}

RECEBIDO EM: 18/07/2019

APROVADO EM: 04/11/2019 